\title{
PRODUÇÃO DO FEIJOEIRO COMUM (Phaseolus vulgaris L.) SOB DIFERENTES DOSES DE FERTILIZANTES
}

Felipe Silva Loosli ${ }^{1}$ Rodrigo Bernardo Soldá ${ }^{3}$, Thadeu Henrique Novais Spósito ${ }^{2}$, Fernando Bernardo Martins ${ }^{1}$, Alline Mendes Alves ${ }^{1}$, Lorrayne Guimarães Bavaresco ${ }^{1}$, Luis Eduardo Vieira Pinto ${ }^{1}$, Patrícia Rafaella de Mello ${ }^{1}$, Wilton Felipe Teixeira ${ }^{1}$

\footnotetext{
${ }^{1}$ Universidade do Oeste Paulista - UNOESTE, Programa de Pós-Graduação em Agronomia, Presidente Prudente, SP.

'Universidade Estadual Paulista "Júlio de Mesquita Filho", Programa de Pós-Graduação em Agronomia, Ilha Solteira, SP

${ }^{3}$ Universidade do Oeste Paulista - UNOESTE, Programa de Residência Agronômica, Presidente Prudente, SP. E-mail: fsloosli@hotmail.com
}

\section{RESUMO}

Considerando a necessidade e exigência nutricional do feijoeiro, o presente trabalho como objetivo avaliar a produção do feijoeiro comum popularmente conhecido como carioca com a aplicação de diferentes doses de fertilizantes. O experimento foi conduzido de quatro tratamentos e cinco repetições, sendo a primeira a testemunha (T1) sem a utilização do fertilizante, (T2) utilizando a quantia recomendada pelo Boletim 100 de acordo com a análise de solo, (T3) fazendo uso de $50 \%$ (metade) da dosagem recomendada e (T4) utilizando a dosagem recomendada e acrescentando $50 \%$ a mais. Foi avaliada as respostas da produtividade e submetidas ao teste de Tuckey e concluído que não houve diferença significativa entre os tratamentos. A testemunha apresentou maior média e esse resultado pode-se inferir que o solo já apresentava boas condições de fertilidade para a produção do feijoeiro comum.

Palavras-chave: Adubação. Produtividade. Leguminosa. Grãos. Fertilidade.

\section{COMMON BEAN (Phaseolus vulgaris L.) PRODUCTION UNDER DIFFERENT DOSES OF FERTILIZERS}

\begin{abstract}
Considering the need and nutritional requirement of the bean, the present work aims to evaluate the production of the common bean popularly known as carioca with the application of different doses of fertilizers. The experiment was conducted with four treatments and five replicates, the first being the control (T1) without the use of the fertilizer, (T2) using the amount recommended by the Bulletin 100 according to the soil analysis, (T3) using $50 \%$ (Half) of the recommended dosage and (T4) using the recommended dosage and adding $50 \%$ more. The productivity responses were evaluated and submitted to the Tuckey test and concluded that there was no significant difference between the treatments. The control group showed a higher mean and this result can be inferred that the soil already had good fertility conditions for common bean production.
\end{abstract}

Keywords: Fertilizing. Productivity. Leguminosa. Grains. Fertility.

\section{INTRODUÇÃO}

O feijão é originário do sul do México, América central, peru, Equador e Bolívia, e foi introduzido na alimentação brasileira pelos negros e índios alguns anos após o descobrimento do Brasil. Assim, os feijões passaram a integrar-se na alimentação cotidiana do brasileiro e fazem 
parte da sua cultura alimentar em todas as classes de renda, tanto nas regiões urbanas quanto no meio rural (VIEIRA et al, 1983).

O feijoeiro comum (Phaseolus vulgaris L.) é uma das principais culturas produzidas no Brasil e no mundo. A sua importância extrapola o aspecto econômico, sendo uns dos mais importantes constituintes da dieta da população brasileira, com grande importância cultural na culinária de diversos países e culturas, sendo também reconhecido como uma excelente fonte proteica, além de possuir bom conteúdo de carboidratos e de ser rico em ferro (VIEIRA et al., 2006).

O feijão comum (Phaseolus vulgaris L.) é cultivado por pequenos e grandes produtores, em diversificados sistemas de produção e em todas as regiões brasileiras. Dependendo do cultivar e da temperatura ambiente, pode apresentar ciclos variando de 65 a 100 dias, o que o torna uma cultura apropriada para compor, desde sistemas agrícolas intensivos irrigados, altamente tecnificados, até aqueles com baixo uso tecnológico, principalmente de subsistência (AIDAR, 2012).

Os feijões são plantas herbáceas, anuais, com morfologia variável, consoante as cultivares. O sistema radicular do feijão é aprumado e superficial, composta de raiz principal da qual se desenvolvem, lateralmente, raízes secundárias, terciárias e raiz possuem nódulos nas raízes laterais devido a simbiose com bactérias fixadoras de nitrogênio. O feijoeiro possui folhas compostas, pecioladas e trifoliadas, as flores possuem um cálice com cinco sépalas e uma coroa de cinco pétalas. $O$ fruto do feijoeiro é uma vagem com características variáveis consoante as cultivares. (VIEIRA et al., 2006).

Segundo Gepts e Fernandez (1982), o desenvolvimento do feijoeiro é separado em duas fases: a vegetativa e a reprodutiva. A vegetativa possui cinco estágios (V0: iniciada a germinação da semente; V1: aparecimento dos cotilédones ao nível do solo; V2: folhas primárias totalmente abertas; V3: abertura da primeira trifoliada e aparecimento da segunda trifoliada). A reprodutiva possui mais cinco estágios (R5: aparecimento do primeiro botão floral e do primeiro rácemo; R6: abertura da primeira flor; R7: surgimento das primeiras vagens; R8: início do enchimento da primeira vagem; R9: maturidade fisiológica).

A busca pelo aumento de produtividade do feijoeiro requer o estabelecimento de estratégias de manejo adequadas as condições locais. A estabilidade do sistema depende não somente da adoção de um conjunto de técnicas, mas sobretudo, da compreensão das ações relativas à interação dos diferentes fatores de produção, no sistema sol-planta-atmosfera (BARBOSA et al., 2012).

A planta do feijoeiro é considerada exigente em nutrientes, para poder expressar todo seu potencial produtivo. Entre os nutrientes essenciais, o nitrogênio é o mais exigido pelo feijoeiro, seguido pelo fosforo e pelo potássio que é exigido pela cultura em menor quantidade. Devido à grande exigência desses nutrientes pelas plantas cultivadas em geral, muitos estudos sobre a sua disponibilidade e eficiência vem sendo feito, visando aumentar a produtividade.

O nitrogênio é o nutriente requerido em maior quantidade pelo feijoeiro. Ele é componente é estrutural de aminoácidos e proteínas, enzimas e coenzimas, ácidos nucleicos entre outros (VIEIRA, 1983). De maneira geral recomenda-se adubação entre 20 e $100 \mathrm{kgha}^{-1}$ de acordo com a análise de solo (VIEIRA et al., 2006).

O fósforo é o nutriente que tem proporcionado as maiores e mais frequentes respostas das culturas (PASTORINI el al., 2000). Na cultura do feijão comum, Miranda et al. (2000) constataram que quanto mais elevados forem os níveis de fósforo, maiores serão suas produtividades e de acordo com Oliveira et al, (1996) para a produção de grãos a aplicação de fósforo aumenta em até $60 \%$ sua produção. 
O potássio tem inúmeras funções nas plantas, destacando-se, principalmente, a ativação de vários sistemas enzimáticos, muitos deles participantes dos processos de fotossíntese e respiração (ERNANI ET AL., 2007). No feijoeiro comum, em condições favoráveis e com absorção ideal de potássio, ele proporciona melhor desenvolvimento dos grãos na maturação e no vigor da semente (OLIVEIRA et al., 1996).

O objetivo deste trabalho é analisar a capacidade de absorção dos nutrientes nas diferentes doses de adubação (ureia, superfosfato simples e cloreto de potássio) e o efeito que a mesma tem sobre o feijoeiro comum observando a produção de grãos.

\section{METODOLOGIA}

O experimento foi realizado para verificar a influência de diferentes doses de adubação por meio da produção de grãos no feijão carioca (Phaseolus vulgaris L.) no dia 27 de junho de 2016 na ETEC Prof. Dr. Antônio Eufrásio de Toledo.

A análise química do solo apresentou os seguintes resultados: Ph 5,4; matéria orgânica

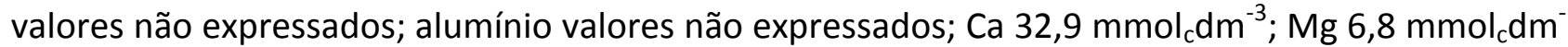
; ; $1,6 \mathrm{mmol}_{\mathrm{C}} \mathrm{dm}^{-3}$; e P $102,5 \mathrm{mmol}_{c} \mathrm{dm}^{-3}$. Como fonte de nutrientes para o teste de efeito de dosagens de macronutrientes (nitrogênio, fósforo e potássio) no plantio os fertilizantes: ureia (como fonte de nitrogênio), superfosfato simples (como fonte de fosforo) e cloreto de potássio (como fonte de potássio).

Foram realizados 4 tratamentos com 5 repetições, e os tratamentos consistiram em: (T1) não recebeu adubação, denominado testemunha; (T2) foi aplicada a dosagem recomendado pela análise de solo (Raij, 2001) utilizando $10,23 \mathrm{kgha}^{-1}$ de $\mathrm{N}_{2}$ na forma de ureia, $20 \mathrm{kgha}^{-1}$ de $\mathrm{P}_{2} \mathrm{O}_{5}$ na forma de superfosfato simples e $18 \mathrm{kgha}^{-1}$ de $\mathrm{K}_{2} \mathrm{O}$ na forma de cloreto de potássio; o tratamento (T3) com metade da dosagem recomendada de T2 e o quarto tratamento foi da dosagem T2 acrescentando mais $50 \%$ dessa quantia.

A semeadura foi realizada em 27/06/2016 com 17 sementes $\mathrm{m}^{-1}$, com espaçamento de 50 $\mathrm{cm}$ entre linhas e cada parcela com área de $15 \mathrm{~m}^{2}$ e o delineamento experimental foi executado em blocos inteiramente casualizados. Foram realizadas aração e gradagem, e o plantio foi feito manualmente com o equipamento popular matraca.Foram feitas duas irrigações via aspersão por dia em toda área e recendo $10 \mathrm{~mm}$ por aplicação. Foram feitas também os tratos culturais necessários para controlar ervas daninhas através de capina.

Após noventa e dois dias do plantio foi realizada a colheita, secagem determinada por meio do método de estufa de $105{ }^{\circ} \mathrm{C}$ por 24 horas (BRASIL, 1992) e separação de impurezas para depois então a pesagem.

\section{RESULTADOS}

Conforme os resultados apresentados na Tabela 1, pode-se observar a produtividade do feijoeiro comum não sofreu influência significativa estatística em função das diferentes fontes de adubação nitrogenada bem como a testemunha, houve um aumento da produtividade, mas não diferença significativa.

Tabela 1: Produtividade em $\mathrm{kgha}^{-1}$

\begin{tabular}{ccccc}
\hline Tratamento & T1 & T2 & T3 & T4 \\
\hline R1 & 0,930 & 0,946 & 0,650 & 0,680 \\
R2 & 1,250 & 0,940 & 0,660 & 0,880 \\
R3 & 0,760 & 0,733 & 0,780 & 0,780 \\
R4 & 0,900 & 0,626 & 0,500 & 0,660 \\
\hline
\end{tabular}




\begin{tabular}{ccccc}
\hline R5 & 0,380 & 0,712 & 1,130 & 0,428 \\
Média & 0,844 & 0,791 & 0,745 & 0,685 \\
\hline
\end{tabular}

Fonte: Autores, 2016

\section{DISCUSSÃO}

A adubação mineral não respondeu significativamente nas condições do experimento. A não resposta da adubação pode ter sido consequência da boa fertilidade já existente no solo ou da lata população de rizóbio e do elevado índice de matéria orgânica, deixados pela cultura anterior plantada no local do experimento. O pousio também promoveu sua recuperação o deixando em boas condições de fertilidade e estrutura física do solo.

De acordo com os resultados obtidos na tabela 1, podemos observar que a maior média foi o tratamento que não recebeu dosagem dos fertilizantes, apresentando resultado satisfatório em relação aos demais tratamentos e média de $846 \mathrm{kgha}^{-1}$ estando entre a média brasileira variando de 800 a $900 \mathrm{kgha}^{-1}$, porém abaixo da produção média do estado de São Paulo com média variando em torno de $1100 \mathrm{kgha}^{-1}$ (IBGE, 2016).

\section{CONCLUSÃO}

Pode se concluir que não houve diferença estatística entre as diferentes dosagens de adubação mineral realizada no plantio do feijoeiro.

\section{REFERÊNCIAS}

AIDAR, H.; KLUTHCOUSKI, J. \& STONE, L.F. Produção de feijoeiro comum em várzeas tropicais. Santo Antônio de Goiás, Embrapa Arroz e Feijão, p. 122-153. 2002.

BARBOSA, F.R.; GONZAGA, A.C.O. informações técnicas para o cultivo do feijoeiro-comum na região central brasileira: 2011/2013 (Série Documentos). Santo Antônio de Goias: Embrapa Arroz e Feijão, p. 15-20, 2012.

BRASIL. Ministério da Agricultura e Reforma Agrária. Regras para análise de sementes. Brasília: SNDA/DNDV/CLAV, 365 p, 1992.

ERNANI, P. R.; ALMEIDA, J. A.; SANTOS, F.C. Potássio. In: NOVAIS, R. F.; ALVARES, V.V.U.; Editora da UFSC, 2000.

GEPTZ, P.; FERNANDEZ, F. Etapas de desarrollo de la planta de frijol comum (Phaseolus vulgaris L.). Cali, Colombia, CIAT. 10p. 1982.

IBGE. Disponível em: http://www.sidra.ibge.gov.br/bda/prevsaf/. Acesso em 24 de outubro, 2016.

MIRANDA, L. N.; AZEVEDO, J. A.; MIRANDA, J. C. C.; GOMES, A. C. Produtividade do feijoeiro em resposta a adubação fosfatada e a regimes de irrigação em solo de cerrado. Pesquisa Agropecuária Brasileira, Brasília, v.35, n.4, p.703-710, 2000. https://doi.org/10.1590/S0100$\underline{204 \times 2000000400005}$

OLIVEIRA, I. P.; ARAUJO, R. S.; DUTRA, L. G.; Nutrição mineral e fixação biológica de nitrogênio.; 1996. 
PASTORINI, L. H.; BACARIN, M. A.; LOPES, N. F.; LIMA, M. G. S. Crescimento inicial de feijoeiro submetido a diferentes doses de fósforo em solução nutritiva. Revista Ceres, 2002. Viçosa, v.47, n.270.; 2000.

VIEIRA, C. Cultura do feijão. 2. ed. Viçosa: Imprensa Universitária da UFV, 1983.

VIEIRA, C.; PAULA JUNIOR, T.J.; BORÉM A. Feijão. Viçosa: UFV, 2006. 